\title{
Downstream and Intermediate Interactions of Synovial Sarcoma-Associated Fusion Oncoproteins and Their Implication for Targeted Therapy
}

\author{
Joanna Przybyl, ${ }^{1,2,3}$ Monika Jurkowska, ${ }^{4}$ Piotr Rutkowski, ${ }^{5}$ \\ Maria Debiec-Rychter, ${ }^{6}$ and Janusz A. Siedlecki ${ }^{1}$ \\ ${ }^{1}$ Department of Molecular Biology, The Maria Sklodowska-Curie Memorial Cancer Centre and Institute of Oncology, \\ 02-781 Warsaw, Poland \\ ${ }^{2}$ Postgraduate School of Molecular Medicine, Warsaw Medical University, 02-091 Warsaw, Poland \\ ${ }^{3}$ Doctoral School of Biomedical Sciences, Catholic University of Leuven, 3000 Leuven, Belgium \\ ${ }^{4}$ Department of Molecular Diagnostics Laboratory, The Maria Sklodowska-Curie Memorial Cancer Centre and Institute of Oncology, \\ 02-781 Warsaw, Poland \\ ${ }^{5}$ Department of Soft Tissue/Bone Sarcoma and Melanoma, The Maria Sklodowska-Curie Memorial Cancer Centre and \\ Institute of Oncology, 02-781 Warsaw, Poland \\ ${ }^{6}$ Department of Human Genetics, Catholic University of Leuven, 3000 Leuven, Belgium
}

Correspondence should be addressed to Joanna Przybyl, joanna.przybyl@coi.pl

Received 25 November 2011; Accepted 9 January 2012

Academic Editor: Alessandro Gronchi

Copyright (C) 2012 Joanna Przybyl et al. This is an open access article distributed under the Creative Commons Attribution License, which permits unrestricted use, distribution, and reproduction in any medium, provided the original work is properly cited.

Synovial sarcoma (SS), an aggressive type of soft tissue tumor, occurs mostly in adolescents and young adults. The origin and molecular mechanism of the development of SS remain only partially known. Over $90 \%$ of SS cases are characterized by the $\mathrm{t}(\mathrm{X} ; 18)(\mathrm{p} 11.2 ; \mathrm{q} 11.2)$ translocation, which results mainly in the formation of SS18-SSX1 or SS18-SSX2 fusion genes. In recent years, several reports describing direct and indirect interactions of SS18-SSX1/SSX2 oncoproteins have been published. These reports suggest that the fusion proteins particularly affect the cell growth, cell proliferation, TP53 pathway, and chromatin remodeling mechanisms, contributing to SS oncogenesis. Additional research efforts are required to fully explore the proteinprotein interactions of SS18-SSX oncoproteins and the pathways that are regulated by these partnerships for the development of effective targeted therapy.

\section{Introduction}

Synovial sarcoma (SS) represents approximately $10 \%$ of soft tissue sarcomas. SS is an aggressive type of tumor, which originates mainly in the extremities but may occur at any anatomic site. Approximately 50\% of SS patients develop metastases, which mainly occur in the lungs. Contrary to the "synovial sarcoma” term, SS has no biological or pathological relation to synovium $[1,2]$. SS is considered as a sarcoma of unknown origin, but recent findings have pointed to either a neural [3], myogenic [4], or multipotent mesenchymal stem cell $[5,6]$. SS occurs in patients at any age but mainly in adolescents and young adults, and it occurs more commonly in males. A single SS case in a human fetus has been re- ported by Duband et al. [7]. Considering histology, SS is either biphasic or monophasic. Biphasic SS has epithelial and spindle cell components in varying proportions [1, 8-11]. The epithelial cells form glands with lumina or papillary structures. The spindle cell component often exists as a monophasic SS, in which spindle cells typically form dense cellular sheets or fascicles. Another rare variant of SS, which is classified as poorly differentiated, is characterized by ovoid or rounded small cells similar to cells in other small round cell tumors. This histological type is associated with the worst clinical outcome $[1,11,12]$. Well-established immunohistochemical markers of SS include epithelial membrane antigen (EMA), transducin-like enhancer protein 1 (TLE1), and cytokeratins (CK7, CK19 and pan-cytokeratin) [13-18]. 
Immunohistochemical analysis is especially important in the differential diagnosis of monophasic and poorly differentiated SS. However, these markers are not specific enough, and the final SS diagnosis is currently frequently supported by cytogenetic or molecular tests.

The first description of $t(X ; 18)$ and the report linking SS with the nonrandom presence of $t(X ; 18)$ were published in $1986[19,20]$. Since 1986, numerous studies have been undertaken to investigate the role of the $t(X ; 18)(p 11.2 ; q 11.2)$ translocation in SS development and maintenance. The characteristic fusion gene found in more than $90 \%$ of SS cases involves the SS18 (previously known as SYT) gene on chromosome 18 and one of the SSX genes on the X chromosome $[9,10,21]$. Nine SSX genes (SSX1-9) have been described, and they are highly homologous. The nucleotide sequence homology of these genes ranges from 87 to $96 \%$, and the amino acid sequence homology ranges from 73 to $92 \%$. The SSX gene family also includes 10 pseudogenes, all of which are located on the X chromosome [22]. The SS18 protein, SSX protein, and SS18-SSX fusion protein are localized in nucleus $[23,24]$.

\section{Function of SS18 and SSX Genes}

SS18 is a ubiquitously expressed gene that encodes a 387amino acid protein. This protein has two functional domains, and both domains are involved in the regulation of transcription. The $\mathrm{SNH}$ domain at the N-terminus is localized between amino acid residues 20 and 73, and it is likely involved in the inhibition of transcriptional activation. The second domain is called the QPGY domain, and it is rich in glutamine, proline, glycine, and tyrosine residues. This domain is localized between amino acid residues 187 and 387, and it has been described as a transcriptional activator (Figure 1). The ribonucleoprotein, SYT-interacting protein/coactivator activator (SIP/CoAA), specifically binds to the QPGY domain of SS18. SIP/CoAA is an RNA splicing modulator and coactivator of transcription, which may point to a hypothetical mechanism of transcriptional regulation by SS18 and the SS18-SSX fusion transcript [25, 26]. Furthermore, the SS18 protein interacts with P300 (a transcriptional coactivator and histone acetyltransferase), which results in the formation of a P300/SS18 complex that regulates cell adhesion [27]. Accordingly, Kimura and coworkers [28] suggested that SS18 may control the expression of P300. Moreover, SS18 has been shown to interact with the following proteins: the leukemia-associated protein, AF10 (also known as MLLT10) [29]; components of the chromatin remodeling complex, including hBRM and BRG1 (also known as SMARCA2 and SMARCA4, resp.) [30, 31] and the growth factor receptor-bound protein, GBR2 [32]. Using mouse cDNA assays for the systematic analysis of protein/protein interactions, Suzuki et al. [33] demonstrated that SS18 interacts with the H3.3A histone. Ito and colleagues [34] reported that the SS18 protein interacts with mSIN3A (a component of histone deacetylase complex), resulting in mSIN3A repression of transcriptional activity mediated by SS18. Kato and coworkers [35] showed that SS18 associates
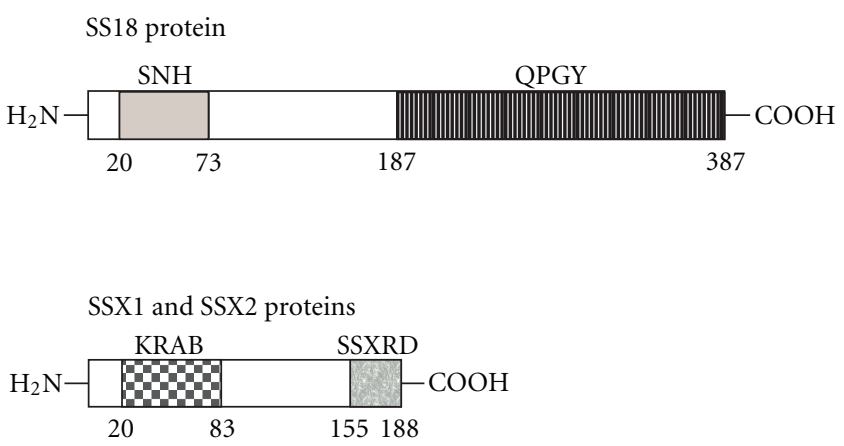

FIgURE 1: Schematic diagram shows the domains structure of SS18 and SSX proteins. The amino acid residues representing the boundaries of selected domains are indicated. SNH-SS18 Nterminal domain; QPGY-SS18 domain rich in glutamine, proline, glycine, and tyrosine; KRAB-SSX Krüppel-associated box domain; SSXRD-SSX transcriptional repression domain.

also with the human SNF/SWI complex, which is a chromatin remodeling factor. Moreover, SS18 has an important role in embryonic development because it participates in the regulation of cell motility and cytoskeletal organization [28]. Furthermore, SS18 affects the expression of genes important for placental development, such as peroxisome proliferatoractivated receptor-binding protein $(P P A R B)$ [36]. The SS18 protein may also have an essential role in epithelial morphogenesis [37].

The SSX1 and SSX2 genes encode proteins consisting of 188 amino acid residues. The SSX genes are normally expressed in the testis and thyroid, and these genes are also expressed in numerous types of human cancers including melanoma [38-40], multiple myeloma [41, 42], nonHodgkin's lymphoma [39], neuroblastoma [43], brain tumors $[39,44]$, various carcinomas of different origin $[39,45-$ 51], and several types of sarcomas (synovial sarcoma, osteosarcoma, and malignant fibrous histiocytoma) [39, 52-57]. SSX1-5 proteins, except for SSX3, are considered cancertestis antigens (CTAs) [39, 40, 48, 58].

SSX proteins have a Krüppel-associated box (KRAB) domain with transcriptional repression activity in their $\mathrm{N}$ terminus. Moreover, SSX proteins possess a transcriptional repressor domain (SSXRD) in their C-terminus (155-188 position), and this domain is also present in the SS18SSX fusion protein (Figure 1) [59]. Interestingly, Dimitriadis et al. [60] reported a single SS case with an unusual fusion transcript lacking the SSXRD domain, which may indicate a more significant role of the SS18 protein in SS18-SSX-associated oncogenesis.

There have been several reports concerning the interactions of the SSX proteins, predominantly with regulators of transcription and polycomb group (PcG) proteins. Soulez and colleagues [61] demonstrated that the SSX1 and SSX2 proteins colocalize with chromatin, and Kato et al. [35] reported that the C-terminal region of the SSX1 protein binds to the core histones. Cronwright and coworkers [62] reported that SSX1-9 proteins participate in cell migration, indicating that these proteins may have an analogical role in cancer metastasis. The interactions of the SSX proteins 
TABLE 1: Interactors of SSX proteins.

\begin{tabular}{|c|c|c|c|}
\hline Gene symbol & Gene description & Function & Reference \\
\hline \multicolumn{4}{|c|}{ SSX1 } \\
\hline FUBP3 & Far upstream element (FUSE) binding protein 3 & Regulation of transcription & {$[151]$} \\
\hline BMI1 & BMI1 polycomb ring finger oncogene & PcG protein-transcriptional repressor & {$[61]$} \\
\hline RING1A & Ring finger protein 1 & PcG protein-transcriptional repressor & {$[61]$} \\
\hline LHX4 & LIM homeobox 4 & Transcription factor & {$[152]$} \\
\hline \multicolumn{4}{|c|}{ SSX2 } \\
\hline BMI1 & BMI1 polycomb ring finger oncogene & PcG protein-transcriptional repressor & {$[61]$} \\
\hline RING1A & Ring finger protein 1 & PcG protein-transcriptional repressor & {$[61]$} \\
\hline $\begin{array}{l}\text { RING1B } \\
(\text { RNF2) }\end{array}$ & Ring finger protein 2 & PcG protein-transcriptional repressor & {$[117]$} \\
\hline$R A B 3 I P$ & RAB3A interacting protein (rabin3) & Protein transport & {$[63,153]$} \\
\hline SSX2IP & Synovial sarcoma, $\mathrm{X}$ breakpoint 2 interacting protein & Cell adhesion & {$[63,153]$} \\
\hline \multicolumn{4}{|c|}{ SSX3 } \\
\hline $\begin{array}{l}\text { DDIT3 } \\
(C H O P)\end{array}$ & DNA-damage-inducible transcript 3 & Transcription factor & {$[151]$} \\
\hline ZBTB25 & Zinc finger and BTB domain containing 25 & Regulation of transcription & {$[151]$} \\
\hline ZBTB3 & Zinc finger and BTB domain containing 3 & Regulation of transcription & {$[151]$} \\
\hline$P C B D 2$ & $\begin{array}{l}\text { Pterin- } 4 \text { alpha-carbinolamine } \\
\text { dehydratase/dimerization cofactor of hepatocyte } \\
\text { nuclear factor } 1 \text { alpha (TCF1) } 2\end{array}$ & Regulation of transcription & {$[151]$} \\
\hline ZNF496 & Zinc finger protein 496 & Regulation of transcription & {$[151]$} \\
\hline ZSCAN1 & Zinc finger and SCAN domain containing 1 & Regulation of transcription & {$[151]$} \\
\hline SSX2IP & Synovial sarcoma, $\mathrm{X}$ breakpoint 2 interacting protein & Cell adhesion & {$[63,153]$} \\
\hline \multicolumn{4}{|c|}{ SSX4 } \\
\hline HIF1A & Hypoxia inducible factor 1 , alpha subunit & Transcription factor & {$[151,153]$} \\
\hline PAX9 & Paired box 9 & Transcription factor & {$[151]$} \\
\hline$X B P 1$ & $\mathrm{X}$-box binding protein 1 & Transcription factor & {$[151]$} \\
\hline LZTR1 & Leucine-zipper-like transcription regulator 1 & Transcription factor & {$[151]$} \\
\hline \multicolumn{4}{|c|}{ SSX5 } \\
\hline NFE2 & Nuclear factor (erythroid-derived 2), $45 \mathrm{kDa}$ & Regulation of transcription & {$[151]$} \\
\hline PCBD2 & $\begin{array}{l}\text { Pterin- } 4 \text { alpha-carbinolamine } \\
\text { dehydratase/dimerization cofactor of hepatocyte } \\
\text { nuclear factor } 1 \text { alpha (TCF1) } 2\end{array}$ & Regulation of transcription & {$[151]$} \\
\hline ZSCAN1 & Zinc finger and SCAN domain containing 1 & Regulation of transcription & {$[151]$} \\
\hline
\end{tabular}

are summarized in Table 1. Interestingly, the RAB3IP and SSX2IP proteins interact with the N-terminal moiety of the SSX2 protein, which is not present in the SS18-SSX fusion protein [63].

\section{SS18-SSX Fusion Types in Synovial Sarcoma}

The SS18-SSX chimeric proteins consist of all but $8 \mathrm{C}$ terminal amino acids of the SS18 protein and $78 \mathrm{C}$-terminal amino acid residues of either the SSX1 or SSX2 protein [64].
The SS18-SSX1 translocation is observed in approximately two-thirds of tumors, and the SS18-SSX2 variant is found in the remaining cases $[10,65,66]$. In addition, rare cases of SS18-SSX4 chimeric variants in SS have been described, but these have been characterized by high breakpoint variability, with a possible functional unpredictability as a consequence. [67-69]. The rare SS cases lacking the classical SS18-SSX fusion gene may represent tumors with unusual variant transcripts, which failed to be detected using conventional approaches [70]. 
The SS18-SSX1 fusion type is mostly associated with biphasic SS and the SS18-SSX2 type strongly correlates with monophasic histology [10, 65, 66, 71, 72]. Saito et al. [73] demonstrated a potential mechanism of such differentiation involving Snail and Slug-the repressors of E-cadherin (CDH1) - which is a crucial determinant of the epithelial phenotype. The loss of E-cadherin has an important role in the epithelial to mesenchymal transition in cancer [74, 75]. The study of Saito and colleagues [73] shows that SS18SSX2 fusion protein interacts preferentially with Slug and SS18-SSX1 fusion protein interacts preferentially with Snail, which is the stronger repressor of the E-cadherin promoter. These observations provide a simplified explanation for the heterogeneity in the acquisition of epithelial characteristics in SS carrying different fusion types.

Both SS18 and SSX proteins lack DNA-binding domains. The most likely mechanism of their function on both a single and fusion protein level is based on the regulation of transcription and on the direct or indirect protein/protein interactions [8]. According to the individual effects of the SS18 and SSX proteins, the SS18-SSX fusion protein may have both transcriptional activation and repression functions [30].

It was long unknown if the presence of the SS18-SSX fusion protein is the only prerequisite for SS formation. A hypothesis has been proposed stating that SS may develop as a result of a series of molecular interactions in which the activity of the SS18-SSX oncoprotein is only a link in a sequence of other events. To elucidate this possible mechanism, Haldar and coworkers [4] created a mouse model of SS by introducing conditional expression of the SS18SSX2 fusion gene in myoblasts. The authors described tumor development in mice that resembled human SS with regard to histological appearance, immunohistochemistry, transcriptional profile, and SS18-SSX2 fusion gene expression in tumor cells. Their findings supported the idea of SS18-SSX translocation as a crucial factor in SS pathogenesis.

Ishida and colleagues [76] demonstrated that SS18SSX1 can form homooligomers via the QPGY domain similarly to the SS18 protein [31]. Moreover, the SS18-SSX1 fusion protein can form heterooligomers with normal SS18 proteins. Based on these findings, a model of SS has been proposed in which target genes controlled by SS18 homooligomers are repressed by the dominant negative function of the SS18-SSX1/SS18 heterooligomers [76].

Several groups have investigated the prognostic value of the different fusion types, with contradicting results. Some studies reported more favorable outcomes in patients with the SS18-SSX2 fusion type [10,65, 71, 77-79], and others failed to find any significant correlation between fusion type and clinical outcome $[66,80,81]$.

\section{Possible Mechanisms in SS Tumorigenesis}

Considering published studies, which present downstream and intermediate targets of SS18-SSX1 and SS18-SSX2 fusion oncoproteins, several molecular pathways in SS development may be proposed. Among the possible mechanisms involved in SS, especially the promotion of cell growth and proliferation, deregulation of the TP53 signaling pathway, and interference of chromatin remodeling should be taken into account.

There is also a single study suggesting that the SS-associated fusion protein causes fundamental changes in the cellular cytoskeleton architecture.

Figure 2 summarizes the possible influence of SS18SSX fusion proteins on described direct and indirect targets, which may contribute to SS tumorigenesis.

\section{SS18-SSX Fusion Proteins Affect Cell Growth and Proliferation}

Several reports indicate cyclin D1, $\beta$-catenin, TP53 pathway components, early growth response protein 1 (EGR1), and insulin-like growth factor 2 (IGF2) together with its receptor IGF-1R as the most important targets of SS18-SSX fusion oncoproteins, involved in the regulation of cell growth and proliferation.

5.1. Cyclin D1 and $\beta$-Catenin. A study conducted by Xie and colleagues [82] focused on the influence of the SS18SSX1 and SS18-SSX2 fusion proteins on tumor-relevant and growth-regulatory proteins, including cyclins A/D1/E, cyclin-dependent kinases (CDKs), p27, and BCL-2 (a protooncogene). $B C L-2$ was expressed at a high level in association with both fusion types. Specifically, SS18-SSX1 was associated with the upregulated expression of cyclins A and D1, and these observations were confirmed by Peng et al. [83]. Upregulation of cyclin D1 has been also associated with SS18-SSX2 fusion type in another study conducted by Xie and colleagues [84]. They suggested that the SS18-SSX2 protein interferes with the ubiquitin-dependent degradation pathway, which results in the upregulation of cyclin D1. An association between the expression level of cyclin D1 and the SS18-SSX2 fusion protein was also investigated by Törnkvist and coworkers [85], who found that the SS18-SSX2 protein is responsible for the maintenance of both cyclin D1 expression and cell proliferation in the examined SS cell lines.

Pretto et al. [86] suggested that $\beta$-catenin is another downstream target of the SS-associated fusion proteins, however they tested only the SS18-SSX2 variant. $\beta$-catenin is an adherent junction-associated protein which connects cadherins to the cytoskeleton. Alternatively, when localized in the nucleus, $\beta$-catenin is an essential effector of the WNT signaling pathway. The misregulation of $\beta$-cateninmediated signaling leads to the development of numerous human malignancies [87]. Pretto et al. [86] demonstrated that SS18-SSX2 stimulates $\beta$-catenin signaling in a P300dependent manner. The fusion transcript recruits $\beta$-catenin to the nucleus, forming a transcriptionally active nuclear complex. Furthermore, the inhibition of SS18-SSX2 expression contributes to the loss of the nuclear $\beta$-catenin signal and a strong decrease of $\beta$-catenin signaling activity. These findings suggest that SS18-SSX2 triggers tumor development partially through the $\beta$-catenin signaling but it should be further investigated whether SS18-SSX1 has the same effect. 


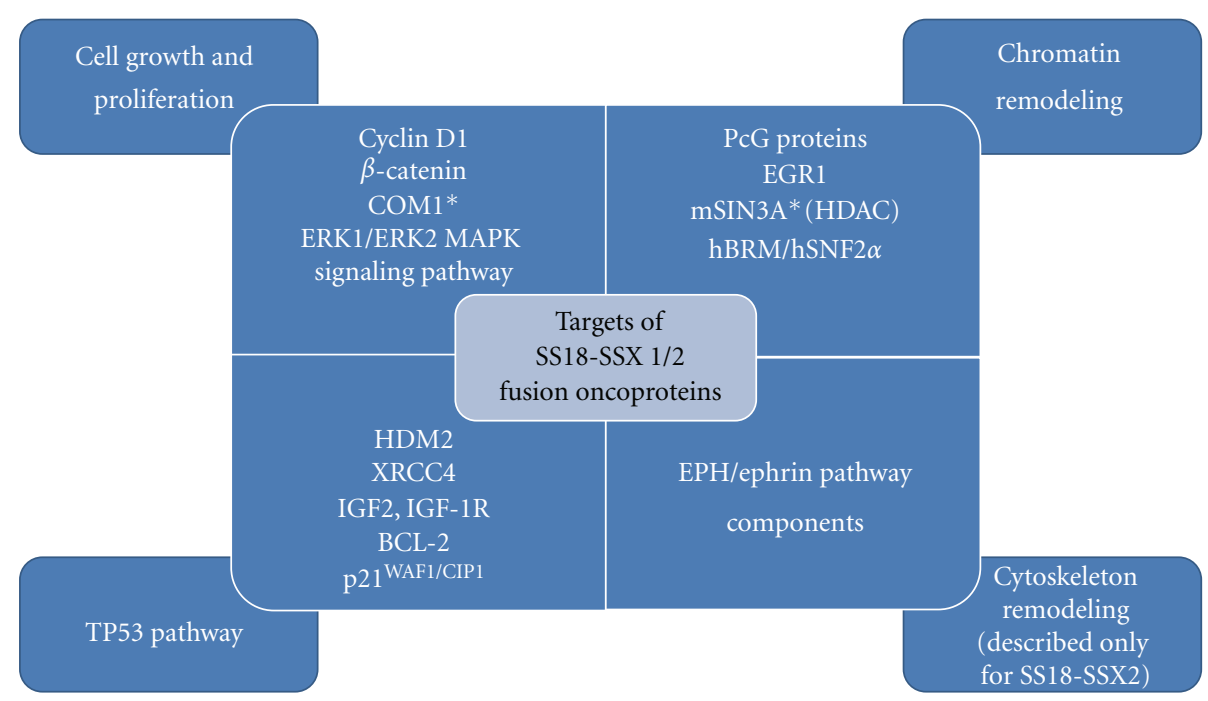

FIGURE 2: Targets of SS18-SSX1/2 fusion oncoproteins involved in cell growth and proliferation, TP53 pathway, chromatin remodeling, and cytoskeleton remodeling, which may contribute to synovial sarcoma tumorigenesis. COM1-candidate of metastasis protein 1; PcGpolycomb group proteins; EGR-early growth response protein 1; mSIN3A-transcriptional regulator; HDAC-histone deacetylase complex; hBRM/hSNF2 $\alpha$-chromatin remodeling complex; TP53-tumor protein p53; HDM2-Mdm2 p53 binding protein homolog (mouse); XRCC4$\mathrm{X}$-ray repair complementing defective repair in Chinese hamster cells 4; IGF2-insulin-like growth factor 2; IGF-1R-insulin-like growth factor 1 receptor; BCL-2-B-cell CLL/lymphoma 2. *Only COM1 and mSIN3A have been described to interact directly with SS18-SSX1/2 fusion proteins.

Interestingly, Horvai and colleagues [88] associated the activation of nuclear $\beta$-catenin with the upregulation of cyclin D1 both in primary and metastatic SS tissue specimens with confirmed $t(X ; 18)$ translocation. A probable mechanism for this upregulation engages $\beta$-catenin and the WNT signaling pathway, which activate the transcription complex involving TCF/LEF. As a result, $\beta$-catenin contributes to the increased cyclin D1 level, which is characteristic of many cancers. These findings agree with the study by Bozzi and coworkers [89] who examined 17 cases of SS in children and adolescents with the confirmed SS18-SSX fusion (11 cases with SS18-SSX1 and 6 cases with SS18-SSX2). They observed nuclear $\beta$-catenin localization in monophasic SS specimens and cyclin D1 overexpression in monophasic and biphasic SS specimens.

5.2. TP53 Pathway. Xie et al. [90] applied the antisense strategy to block the expression of the SS18-SSX2 fusion gene in SS cells, and they reported that the expression of X-ray repair complementing defective repair in Chinese hamster cells 4 (XRCC4) is significantly decreased in such conditions. The unfixed DNA damage in SS may activate the TP53 checkpoint pathway to induce growth arrest or apoptosis. This experiment has been conducted only in one SS cell line carrying SS18-SSX2 transcript, but two other studies of D'Arcy and coworkers demonstrated that TP53 is affected in cell lines expressing both SS18-SSX1 and SS18SSX2. Firstly, they demonstrated that SS18-SSX1 promotes TP53 ubiquitination and degradation by a mechanism involving the HDM2 (Mdm2 p53 binding protein homolog in mouse). The fusion protein inhibited autoubiquitination and increased the half-life of HDM2, making it more stable in cells [91]. A subsequent study confirmed that TP53 is specifically affected by HDM2 also in SYO- 1 cell line, derived from biphasic SS and carrying SS18-SSX2, which presented the increase of TP53 stability, activation of TP53 target genes, growth arrest, and apoptosis upon treatment with HDM2 antagonist [92]. Another observation [91] was that SS18-SSX1 attenuates the TP53 response and changes the expression levels of several TP53-regulated genes, such as $B B C 3$ (BCL2 binding component 3) and PMAIP1 (phorbol12-myristate-13-acetate-induced protein 1), but it does not affect the expression level of the $\mathrm{p} 21^{\mathrm{WAFI} / \mathrm{CIP} 1}$ (also known as CDKN1A-cyclin-dependent kinase inhibitor 1A). However, contradictory results have been published by Tsuda and coworkers [93] who reported that SS18-SSX1 upregulates $\mathrm{p} 21^{\mathrm{WAF} 1 / \mathrm{CIP} 1}$ protein in the manner independent of the hBRM chromatin remodeling factor and TP53 but dependent on the SP1/SP3 transcription factors.

5.3. EGR1. Lubieniecka and coworkers [94] reported that the SS18-SSX2 fusion protein inhibits a cancer-related gene EGR1 through repressive histone modifications and recruitment of PcG proteins. EGR1 encodes a serum-inducible zinc finger protein, which is crucial for cell proliferation, differentiation and apoptosis. The same group demonstrated that EGR1 is a target of the fusion protein but they only examined two cell lines carrying SS18-SSX2 fusion variant. No cell line expressing SS18-SSX1 fusion gene has been included in the study. The downregulation of EGR1 in SS has also been observed in cDNA microarray experiments [94, 95]. Moreover, Su et al. [96] demonstrated that EGR1 affects the expression of phosphatase and tensin homolog deleted in chromosome 10 (PTEN), which is a tumor suppressor gene and an important phosphatase that regulates the PI3K/AKT survival pathway. Both EGR1 and PTEN have been reported 
to be downregulated by the specific microRNA, miR-183, and the elevated level of miR-183 has been observed in SS and other tumor types [97]. These data suggest the important role of the EGR1 and PTEN tumor suppressors in SS oncogenesis.

5.4. IGF2 and IGF-1R. IGF2 is another target of the SS18SSX fusion proteins. Upregulation of this gene has been associated with the expression of both SS18-SSX1 and SS18-SSX2 fusion proteins $[95,98,99]$. Upregulation of IGF2 is necessary for tumor formation in vivo and for the proliferation of cultured SS cells $[99,100]$. The antiapoptotic and mitogenic function of IGF2 is mediated by IGF-1R, and the expression of this receptor has been also demonstrated in SS cell lines and tumor specimens bearing SS18-SSX1 and SS18-SSX2 fusion proteins [85, 100-102]. In addition, Friedrichs et al. [100] reported that also AKT and p44/42 MAPK (elements of IGF-1R-related signaling pathways) were activated in the analyzed tumor specimens. Although IGF2 has an important role in SS, the overexpression of IGF2 is not exclusive to this sarcoma subtype. For example, several expression profiling studies have demonstrated IGF2 overexpression as a characteristic feature of gastrointestinal stromal tumors (GISTs) and rhabdomyosarcomas [103-106].

The cell proliferation regulator, candidate of metastasis 1 (COM1), also known as $p 8$ or nuclear protein transcriptional regulator 1 (NUPR1), and ERK1/ERK2 MAPK signaling pathway components have been proposed as other possible targets of SS18-SSX fusion proteins, involved in the cell proliferation regulation. However, there are only single reports describing their role in SS.

Ishida et al. [76] observed that both SS18-SSX1/2 fusion oncoproteins directly downregulate the expression of COM1, which is expressed at low level both in cell lines carrying different types of translocation, as well as in SS tumor specimens. The authors demonstrated also that the knockdown of SS18-SSX2 results in a strong upregulation of COM1 expression, which reduces in vitro cell growth and colony formation of SYO-1 cell line. Additionally, the restoration of COM1 expression induced apoptosis in this cell line. Overall, their results indicated that the maintenance of COM1 expression at a low level has an important role in SS growth.

Cai et al. [107] performed RNA interference experiments targeting the 19-nucleotide sequence of SS18-SSX2 mRNA in SYO-1 cells, demonstrating that downregulation of the fusion gene inhibits cell proliferation and diminishes the protein levels of ERK1, ERK2, p-ERK, and cyclin D1.

\section{SS18-SSX Fusion Proteins Are Involved in Chromatin Remodeling}

PcG proteins, histone deacetylase complex (HDAC), and hBRM/hSNF $2 \alpha$ complex are the most important targets of SS18-SSX fusion oncoproteins involved in chromatin remodeling.

6.1. Polycomb Group Proteins. PcG proteins are involved in the repression of gene transcription through the modulation of chromatin structure. Functional deregulation of polycomb complexes has been previously demonstrated during cancer progression. The polycomb complex is usually involved in tumorigenesis as a result of its upregulation [108-110]. However, downregulation of the polycomb complex has been described in germ cell tumors [111] and some breast tumors [112].

According to the study of dos Santos and colleagues [113], SSX2 and both SS18-SSX1/2 proteins colocalize with PcG proteins. Specifically, co-localization of SS18-SSX1 and SS18-SSX2 fusion proteins with RING1 proteins, SS18-SSX2 fusion proteins with HPC2 proteins, and SSX2 proteins with RING1 proteins, BMI1 proteins and chromatin have been reported. However, these colocalizations are not the result of direct physical interactions. These findings were consistent with a study by Soulez et al. [61] who demonstrated that SSX1, SSX2, SS18-SSX1, and SS18-SSX2 proteins colocalize with BMI1 and that SSX1, SSX2, and SS18-SSX2 proteins colocalize with chromatin. Moreover, colocalization of SS18SSX2 fusion proteins with RING1 proteins has also been observed. Yet, Western blot analysis did not confirm the direct interactions of these proteins [61]. Furthermore, polycomb deregulation by SS18-SSX fusion proteins has been demonstrated in two other studies. Cironi and colleagues [98] showed that the polycomb target genes appear to be affected by the expression of SS18-SSX1. Barco et al. [114] reported that the SS18-SSX2 fusion protein modulates the silencing activity of the polycomb repressive complex and destabilizes BMI1 proteins, leading to the impairment of polycomb-dependent histone $\mathrm{H} 2 \mathrm{~A}$ ubiquitination and reactivation of the polycomb target genes.

6.2. Histone Deacetylase Complex (HDAC). Ito and colleagues [34] observed that SS18 and SS18-SSX1 proteins (but not SS18-SSX2 protein) can bind mSIN3A proteins, which are a part of the histone deacetylase complex (HDAC). HDAC affects gene expression by acting on chromatin through transcriptional factors, corepressors and methylCpG binding proteins. Based on these findings, Ito et al. [115] further investigated the impact of the histone deacetylase inhibitor, FK228, on SS growth both in vitro and in vivo. They examined cell lines carrying both the SS18-SSX1 and SS18-SSX2 fusion proteins. As a result of treatment with the FK228 inhibitor, the growth of cultured SS cells and SS xenografts in mice was significantly reduced. Also tumor weight and tumor density decreased after FK228 treatment. Remarkably, cells carrying the SS18-SSX2 fusion protein were more sensitive than those carrying the SS18-SSX1 one.

6.3. hBRM/hSNF2 $\alpha$ Complex. Nagai and coworkers [116] assessed the transforming activity of the SS18-SSX1 fusion protein, and they correlated the growth rate of the cells with the expression level of the SS18, SSX1, and SS18-SSX1 genes introduced into three independent clones of $3 \mathrm{Y} 1 \mathrm{rat}$ fibroblast cell lines. $3 Y 1$ cells expressing SS18-SSX2 fusion gene were not included in the study. The researchers reported that the human SS18-SSX1 fusion gene imposed the highest growth rate among the genes tested. Furthermore, they 
established the association between the SS18-SSX1 protein and the chromatin remodeling complex, hBRM/hSNF $2 \alpha$. They proposed that this complex has an essential role in SS18-SSX1-induced transformation, suggesting that it may downregulate the deleted in colorectal carcinoma (DCC) tumor suppressor.

\section{SS18-SSX2 Fusion Protein and Its Role in Cytoskeleton Remodeling}

Barco et al. [117] presented another possible mechanism of carcinogenesis triggered by the SS18-SSX2 fusion oncoprotein. They reported that SS18-SSX2 stabilizes the microtubule network and stimulates the expression and activation of EPH/ephrin pathway components. The EPH/ephrin system is involved in the regulation of cytoarchitecture and determination of cell position during development and tissue regeneration. In tumors, the EPH/ephrin system has been linked to angiogenesis, loss of cell adhesion, and enhanced migration. Overall, the study suggested that the SS18-SSX2 fusion protein causes fundamental changes in the cellular cytoskeleton architecture; however, this mechanism has not been investigated in cells carrying SS18-SSX1 fusion transcript.

\section{Discussion}

8.1. Development of Targeted Therapy for Synovial Sarcoma. Based on the assumption that cancer-related pathways and proteins that are upregulated in SS may serve as possible therapeutic targets, a few important directions should be considered. Bozzi and colleagues [89] showed that EGFR and platelet-derived growth factor receptors (PDGFRA and PDGFRB) are upregulated in SS with subsequent PI3K/AKT/ mTOR pathway activation. Consecutive reports by Dobashi et al. [118] and Friedrichs et al. [119] also demonstrated the activation of the PI3K/AKT/mTOR pathway in SS. These reports suggest that inhibitors of the PI3K/AKT/mTOR pathway may be used for a potential therapy of SS through the repression of multiple upstream targets of this pathway. Several other studies have confirmed the upregulation of the receptor tyrosine kinases EGFR, PDGFRA and PDGFRB in SS that can be targeted by specific small molecule inhibitors [120-127]. HER-2/neu, BCL-2, and fibroblast growth factor receptor 2 (FGFR2) are among other proteins considered as potential targets in SS $[6,17,82,122,128]$. Additionally, IGF$1 \mathrm{R}$ may be a suitable target in SS therapy, and therapeutic antibodies against IGF-1R and small molecules inhibiting the tyrosine kinase activity of IGF-1R have been already developed [85, 101, 129].

Since the presence of SS18-SSX fusion proteins is a proven prerequisite for SS oncogenesis, a detailed insight into the mechanisms of their interactions may contribute to the development of targeted therapies, which are still unavailable for SS patients. Several direct effectors of SS18SSX fusion proteins in SS have been already confirmed but they have not yet been examined as potential therapeutic targets. Thus, it may be reasonable to undertake new studies with the following aims: (1) to accurately characterize the nature of these interactions, including the domains or amino acid residues involved; (2) to screen small molecule libraries to detect potential molecules that interrupt selected interactions; (3) to test selected small molecules in synovial sarcoma animal models; (4) to transfer these results to clinical trials. Such strategy is reasonable especially in the light of recent findings made by Erkizan and coworkers [130] who identified a small molecule inhibitor of EWS-FLI1 fusion transcript interaction with RNA helicase A (RHA), which is important in the oncogenesis of Ewing's sarcoma family tumors (ESFTs).

Moreover, the SS18 and SSX proteins have been described to individually interact with several important regulators of transcription. Hence, it is rational to test in the future studies whether the SS18-SSX fusion proteins also interact with these molecules. Among proteins that colocalize both with SSX and SS18-SSX are PcG proteins, which appear to be an interesting target in synovial sarcoma therapy. The important role of PcG proteins in oncogenesis has been already extensively reviewed $[131,132]$ and some recent publications support their use as molecular targets in anticancer therapy. Dimri and coworkers [133] showed that the aberrant expression of PcG protein enhancer of zeste homologue 2 (EZH2) can be suppressed by dietary omega-3 polyunsaturated fatty acids (PUFAs), leading to decrease in the invasion potential of breast cancer cells. Another study published by Kemp and colleagues [134] demonstrated that pharmacological inhibition of polycomb repressor complex-2 (PRC-2) is a successful therapeutic strategy in malignant pleural mesothelioma. Even though RING1 and BMI1 proteins which colocalize with SSX and SS18-SSX are the components of another polycomb repressor complex-1 (PRC-1), the abovementioned results provide rationale to test the influence of PRC-1 inhibition on the synovial sarcoma oncogenesis.

As of yet, the completed clinical trials investigating the role of selected targets in SS did not point to any successful therapeutic strategy. A phase II study conducted by the European Organization for Research and Treatment of Cancer (EORTC) Soft Tissue and Sarcoma Group demonstrated that gefitinib treatment specifically targeting EGFR failed in SS patients [135]. The reports about EGFR upregulation in SS have not indicated any direct interaction or association with the SS18-SSX1 or SS18-SSX2 fusion proteins which might explain why inhibition of EGFR pathway was not successful in SS treatment $[122,126]$. However, gefitinib was the only EGFR inhibitor examined thus far in SS and the efficacy of other small molecule EGFR inhibitors remain to be explored. Similarly in reference to the upregulation of PDGFRA/B in SS, a phase II study assessing imatinib efficacy in 10 sarcoma subtypes determined that it is not an active agent in SS [136]. Nonetheless, another phase Ib/II clinical trial has been undertaken to examine the efficacy of imatinib in combination with mTOR inhibitor everolimus in SS patients (NCT01281865). Another ongoing phase II study including SS patients aims to evaluate the combined use of mTOR inhibitor temsirolimus with IGF-1R monoclonal antibody cixutumumab (NCT01016015). Furthermore, there are two phase II clinical trials in progress includ- ing SS 
patients, which examine the treatment with HDAC inhibitors (NCT01112384 and NCT01136499). Hopefully the results of these trials will shed more light on possible directions in SS targeted therapy.

8.2. Hypothetical Network of Interactions. Interestingly, there have been several reports demonstrating interactions between the various genes and proteins mentioned in this review without reference to SS development or SS maintenance. Many of the SS18-SSX1/2 targets, such as COM1, HDM2, cyclin D1, and EGR1, have been described to interact with P300 proteins [137-141]. In addition, HDM2 may interact with p $21^{\mathrm{WAF} 1 / \mathrm{CIP} 1}$ and may associate with chromatin [142]. Furthermore, the nuclear epidermal growth factor receptor (EGFR) participates in cyclin D1 transcription [143], and cyclins D1 and A bind to p21 WAF1/CIP1 [144]. Tsuda et al. [93] described that the upregulation of $\mathrm{p} 21^{\mathrm{WAF} 1 / \mathrm{CIP} 1}$ is dependent on the SP1/SP3 transcription factors. Importantly, the SP1 transcription factor interacts with EGR1, HDM2 and TP53, which are all implicated in SS tumorigenesis via SS18-SSX1/2 fusion proteins [145-150]. Further studies of these potential interactions in the context of SS should be conducted; they may provide a broader perspective on oncogenic pathways in SS.

8.3. SS18-SSX1 versus SS18-SSX2. As far as pathways involving cell growth, cell proliferation, TP53, and chromatin remodeling are concerned, it has been shown that both the SS18-SSX1 and SS18-SSX2 fusion proteins may interfere with them, but often through distinct molecular interactions. The cytoskeleton remodeling mechanism has been examined exclusively for the SS18-SSX2 fusion type. It should be taken into consideration that there has been still a relatively small number of studies conducted to determine downstream and intermediate targets of SS18-SSX1/2 fusion oncoproteins. Probably many of their interactions and direct effects remain unknown.

Notably, it is important to distinguish between the SS18SSX1 and SS18-SSX2 oncoproteins while studying the role of the fusion transcript in SS formation. Both by functional and expression profiling studies, it has been shown that these proteins may have distinct molecular activities even though their sequences are highly homologous and they induce tumors with similar pathological features. Inagaki et al. [77] compared the impact of SS18-SSX1 and SS18-SSX2 fusion types on the expression level of several tumor cell proliferation-associated genes and other tumor-related pathological parameters in SS primary tumor specimens. As compared to the SS18-SSX2 fusion protein, the SS18-SSX1 fusion protein is related to higher mitotic rate and higher proliferation index as measured by Ki-67 staining. In turn, Fernebro and coworkers [11] conducted gene expression profiling studies to determine gene expression differences between SS18-SSX1 and SS18-SSX2 SS variants. Among the upregulated genes associated with the SS18-SSX1 fusion protein they listed genes involved in oncogenesis, such as TCF7, ZIC2, IGFBP3, SPAG7, AGRN, VIL2, AXL, RALGDS, and $C D C 2 L I$, in addition to genes encoding metalloth- ioneins, histones and $\mathrm{G}$ protein-coupled receptors. Genes characteristically overexpressed in SS with the SS18-SSX2 fusion type include FOXC1, GAS1, and NCAM1.

Because SS specimens carrying different SS18-SSX fusion proteins may have distinct molecular characteristics, it seems inappropriate to formulate conclusions about the function of the SS18-SSX fusion protein based on the results obtained only for one fusion type. Moreover, some reports describe a general role of the SS18-SSX fusion protein even though the actual fusion type was not defined or may have been only presumed from the SS cell line used in the particular experiment. In the search for the functions of SS18-SSX1 and SS18-SSX2, it is necessary to conduct studies that include cell lines or tumor specimen groups with different types of fusion proteins, allowing their possible heterogeneous molecular functions to be recognized.

Current state of the SS research indicates that SS18SSX fusion proteins deregulate mostly cell growth, cell proliferation, TP53 pathway, and chromatin remodeling mechanisms. Several molecules involved in these pathways occur to be emerging therapeutic targets, especially those directly interacting with SS-associated fusion proteins. It is crucial for the prospective clinical trials to select potential therapeutic targets on the basis of functional studies that explore the critical drivers of SS oncogenesis. However, many aspects of SS tumorigenesis and network of SS18-SSX fusion proteins interactions remain to be elucidated.

\section{Acknowledgments}

The project was conducted within the International Ph.D. Projects Program (MPD) of the Foundation for Polish Science, and it was cofinanced by the European Union Regional Development Fund. This work was supported by the Polish Ministry of Science Grant no. N N402 686640.

\section{References}

[1] A. A. Sandberg and J. A. Bridge, "Updates on the cytogenetics and molecular genetics of bone and soft tissue tumors: chondrosarcoma and other cartilaginous neoplasms," Cancer Genetics and Cytogenetics, vol. 143, no. 1, pp. 1-31, 2003.

[2] C. Fukukawa, Y. Nakamura, and T. Katagiri, "Molecular target therapy for synovial sarcoma," Future Oncology, vol. 1, no. 6, pp. 805-812, 2005.

[3] T. Ishibe, T. Nakayama, T. Aoyama, T. Nakamura, and J. Toguchida, "Neuronal differentiation of synovial sarcoma and its therapeutic application," Clinical Orthopaedics and Related Research, vol. 466, no. 9, pp. 2147-2155, 2008.

[4] M. Haldar, J. D. Hancock, C. M. Coffin, S. L. Lessnick, and M. R. Capecchi, "A conditional mouse model of synovial sarcoma: insights into a myogenic origin," Cancer Cell, vol. 11, no. 4, pp. 375-388, 2007.

[5] N. Naka, S. Takenaka, N. Araki et al., "Synovial sarcoma is a stem cell malignancy," Stem Cells, vol. 28, no. 7, pp. 1119$1131,2010$.

[6] C. B. Garcia, C. M. Shaffer, M. P. Alfaro et al., "Reprogramming of mesenchymal stem cells bythe synovial sarcoma-associated oncogene SYT-SSX2," Oncogene. In press. 
[7] S. Duband, A. L. Morrison, D. Pasquier, J. M. Coindre, B. Pasquier, and M. Péoc'h, "First case report of a fetal synovial sarcoma confirmed by molecular detection of SYT-SSX fusion gene transcripts," American Journal of Perinatology, vol. 25, no. 8, pp. 517-520, 2008.

[8] M. Ladanyi, "Fusions of the SYT and SSX genes in synovial sarcoma," Oncogene, vol. 20, no. 40, pp. 5755-5762, 2001.

[9] I. Panagopoulos, F. Mertens, M. Isaksson et al., "Clinical impact of molecular and cytogenetic findings in synovial sarcoma," Genes Chromosomes and Cancer, vol. 31, no. 4, pp. 362372, 2001.

[10] M. Ladanyi, C. R. Antonescu, D. H. Leung et al., "Impact of SYT-SSX fusion type on the clinical behavior of synovial sarcoma: a multi-institutional retrospective study of 243 patients," Cancer Research, vol. 62, no. 1, pp. 135-140, 2002.

[11] J. Fernebro, P. Francis, P. Edén et al., "Gene expression profiles relate to SS18/SSX fusion type in synovial sarcoma," International Journal of Cancer, vol. 118, no. 5, pp. 1165-1172, 2006.

[12] R. Nakayama, S. Mitani, T. Nakagawa et al., "Gene expression profiling of synovial sarcoma: distinct signature of poorly differentiated type," American Journal of Surgical Pathology, vol. 34, no. 11, pp. 1599-1607, 2010.

[13] M. Miettinen, "Keratin subsets in spindle cell sarcomas. Keratins ae widespread but synovial sarcoma contains a distinctive keratin polypeptide pattern and desmoplakins," American Journal of Pathology, vol. 138, no. 2, pp. 505-513, 1991.

[14] M. Pelmus, L. Guillou, I. Hostein, G. Sierankowski, C. Lussan, and J. M. Coindre, "Monophasic fibrous and poorly differentiated synovial sarcoma: immunohistochemical reassessment of $60 \mathrm{t}(\mathrm{X} ; 18)$ (SYT-SSX)-positive cases," American Journal of Surgical Pathology, vol. 26, no. 11, pp. 14341440, 2002.

[15] S. H. Olsen, D. G. Thomas, and D. R. Lucas, "Cluster analysis of immunohistochemical profiles in synovial sarcoma, malignant peripheral nerve sheath tumor, and Ewing sarcoma," Modern Pathology, vol. 19, no. 5, pp. 659-668, 2006.

[16] J. Terry, T. Saito, S. Subramanian et al., "TLE1 as a diagnostic immunohistochemical marker for synovial sarcoma emerging from gene expression profiling studies," American Journal of Surgical Pathology, vol. 31, no. 2, pp. 240-246, 2007.

[17] A. Jagdis, B. P. Rubin, R. R. Tubbs, M. Pacheco, and T. O. Nielsen, "Prospective evaluation of TLE1 as a diagnostic immunohistochemical marker in synovial sarcoma," American Journal of Surgical Pathology, vol. 33, no. 12, pp. 17431751, 2009.

[18] T. Knösel, S. Heretsch, A. Altendorf-Hofmann et al., "TLE1 is a robust diagnostic biomarker for synovial sarcomas and correlates with $\mathrm{t}(\mathrm{X} ; 18)$ : analysis of 319 cases," European Journal of Cancer, vol. 46, no. 6, pp. 1170-1176, 2010.

[19] J. Limon, P. Dal Cin, and A. A. Sandberg, "Translocations involving the $\mathrm{X}$ chromosome in solid tumors: presentation of two sarcomas with t[X;18] [q13;p11]," Cancer Genetics and Cytogenetics, vol. 23, no. 1, pp. 87-91, 1986.

[20] C. Turc-Carel, P. Dal Cin, J. Limon, F. Li, and A. A. Sandberg, "Translocation X;18 in synovial sarcoma," Cancer Genetics and Cytogenetics, vol. 23, no. 1, p. 93, 1986.

[21] F. Mitelman, B. Johansson, and F. Mertens, Eds., "Mitelman database of chromosome aberrations in cancer," 2011, http://cgap.nci.nih.gov/Chromosomes/Mitelman .

[22] A. O. Güre, I. J. Wei, L. J. Old, and Y. T. Chen, "The SSX gene family: characterization of 9 complete genes," International Journal of Cancer, vol. 101, no. 5, pp. 448-453, 2002.
[23] D. Brett, S. Whitehouse, P. Antonson, J. Shipley, C. Cooper, and G. Goodwin, "The SYT protein involved in the $\mathrm{t}(\mathrm{X} ; 18)$ synovial sarcoma translocation is a transcriptional activator localised in nuclear bodies," Human Molecular Genetics, vol. 6, no. 9, pp. 1559-1564, 1997.

[24] N. R. dos Santos, D. R. H. de Bruijn, M. Balemans et al., "Nuclear localization of SYT, SSX and the synovial sarcomaassociated SYT-SSX fusion proteins," Human Molecular Genetics, vol. 6, no. 9, pp. 1549-1558, 1997.

[25] M. Perani, P. Antonson, R. Hamoudi et al., "The protooncoprotein SYT interacts with SYT-interacting protein/coactivator activator (SIP/CoAA), a human nuclear receptor co-activator with similarity to EWS and TLS/FUS family of proteins," Journal of Biological Chemistry, vol. 280, no. 52, pp. 42863-42876, 2005.

[26] T. Iwasaki, N. Koibuchi, and W. W. Chin, "Synovial sarcoma translocation (SYT) encodes a nuclear receptor coactivator," Endocrinology, vol. 146, no. 9, pp. 3892-3899, 2005.

[27] J. E. Eid, A. L. Kung, R. Scully, and D. M. Livingston, "p300 Interacts with the nuclear proto-oncoprotein SYT as part of the active control of cell adhesion," Cell, vol. 102, no. 6, pp. 839-848, 2000.

[28] T. Kimura, M. Sakai, K. Tabu et al., "Human synovial sarcoma proto-oncogene Syt is essential for early embryonic development through the regulation of cell migration," Laboratory Investigation, vol. 89, no. 6, pp. 645-656, 2009.

[29] D. R. H. de Bruijn, N. R. Dos Santos, J. Thijssen et al., “The synovial sarcoma associated protein SYT interacts with the acute leukemia associated protein AF10," Oncogene, vol. 20, no. 25, pp. 3281-3289, 2001.

[30] C. Thaete, D. Brett, P. Monaghan et al., "Functional domains of the SYT and SYT-SSX synovial sarcoma translocation proteins and co-localization with the SNF protein BRM in the nucleus," Human Molecular Genetics, vol. 8, no. 4, pp. 585591, 1999.

[31] M. Perani, C. J. E. Ingram, C. S. Cooper, M. D. Garrett, and G. H. Goodwin, "Conserved SNH domain of the protooncoprotein SYT interacts with components of the human chromatin remodelling complexes, while the QPGY repeat domain forms homo-oligomers," Oncogene, vol. 22, no. 50, pp. 8156-8167, 2003.

[32] S. Bandyopadhyay, C. Y. Chiang, J. Srivastava et al., "A human MAP kinase interactome," Nature Methods, vol. 7, no. 10, pp. 801-805, 2010.

[33] H. Suzuki, Y. Fukunishi, I. Kagawa et al., "Protein-protein interaction panel using mouse full-length cDNAs," Genome Research, vol. 11, no. 10, pp. 1758-1765, 2001.

[34] T. Ito, M. Ouchida, S. Ito et al., "SYT, a partner of SYT-SSX oncoprotein in synovial sarcomas, interacts with $\mathrm{mSin} 3 \mathrm{~A}$, a component of histone deacetylase complex," Laboratory Investigation, vol. 84, no. 11, pp. 1484-1490, 2004.

[35] H. Kato, A. Tjernberg, W. Zhang et al., "SYT associates with human SNF/SWI complexes and the C-terminal region of its fusion partner SSX1 targets histones," Journal of Biological Chemistry, vol. 277, no. 7, pp. 5498-5505, 2002.

[36] D. R. H. de Bruijn, W. J. M. Peters, S. M. Chuva de Sousa Lopes et al., "Targeted disruption of the synovial sarcomaassociated SS18 gene causes early embryonic lethality and affects PPARBP expression," Human Molecular Genetics, vol. 15, no. 19, pp. 2936-2944, 2006.

[37] M. Chittezhath, A. L. Frump, J. Jourquin, N. Lobdell, and J. E. Eid, "The proto-oncoprotein SYT (SS18) controls ATP release and regulates cyst formation by polarized MDCK 
cells," Experimental Cell Research, vol. 314, no. 19, pp. 35513562, 2008.

[38] A. O. Güre, O. Türeci, U. Sahin et al., "SSX: a multigene family with several members transcribed in normal testis and human cancer," International Journal of Cancer, vol. 72, no. 6, pp. 965-971, 1997.

[39] O. Türeci, Y. T. Chen, U. Sahin et al., "Expression of SSX genes in human tumors," International Journal of Cancer, vol. 77, no. 1, pp. 19-23, 1998.

[40] N. R. dos Santos, R. Torensma, T. J. De Vries et al., "Heterogeneous expression of the SSX cancer/testis antigens in human melanoma lesions and cell lines," Cancer Research, vol. 60, no. 6, pp. 1654-1662, 2000.

[41] B. J. Taylor, T. Reiman, J. A. Pittman et al., "SSX cancer testis antigens are expressed in most multiple myeloma patients: co-expression of SSX1, 2, 4, and 5 correlates with adverse prognosis and high frequencies of SSX-positive PCs," Journal of Immunotherapy, vol. 28, no. 6, pp. 564-575, 2005.

[42] V. C. Andrade, A. L. Vettore, R. S. Felix et al., "Prognostic impact of cancer/testis antigen expression in advanced stage multiple myeloma patients," Cancer Immunity, vol. 8, p. 2, 2008.

[43] S. N. Chi, N. K. V. Cheung, and I. Y. Cheung, "Expression of SSX-2 and SSX-4 genes in neuroblastoma," International Journal of Biological Markers, vol. 17, no. 4, pp. 219-223, 2002.

[44] M. H. Lee, E. I. Son, E. Kim, I. S. Kim, M. B. Yim, and S. P. Kim, "Expression of cancer-testis genes in brain tumors," Journal of Korean Neurosurgical Society, vol. 43, no. 4, pp. 190-193, 2008.

[45] K. Hasegawa, F. Koizumi, Y. Noguchi et al., "SSX expression in gynecological cancers and antibody response in patients," Cancer Immunity, vol. 4, p. 16, 2004.

[46] T. Utsunomiya, H. Inoue, F. Tanaka et al., "Expression of cancer-testis antigen (CTA) genes in intrahepatic cholangiocarcinoma," Annals of Surgical Oncology, vol. 11, no. 10, pp. 934-940, 2004.

[47] J. R. Peng, H. S. Chen, D. C. Mou et al., "Expression of cancer/testis (CT) antigens in Chinese hepatocellular carcinoma and its correlation with clinical parameters," Cancer Letters, vol. 219, no. 2, pp. 223-232, 2005.

[48] L. Q. Wu, Y. Lu, X. F. Wang, Z. H. Lv, B. Zhang, and J. Y. Yang, "Expression of cancer-testis antigen (CTA) in tumor tissues and peripheral blood of Chinese patients with hepatocellular carcinoma," Life Sciences, vol. 79, no. 8, pp. 744-748, 2006.

[49] D. Valmori, F. Qian, M. Ayyoub et al., "Expression of synovial sarcoma X (SSX) antigens in epithelial ovarian cancer and identification of SSX-4 epitopes recognized by CD4+ T cells," Clinical Cancer Research, vol. 12, no. 2, pp. 398-404, 2006.

[50] J. A. Dubovsky and D. G. McNeel, "Inducible expression of a prostate cancer-testis antigen, SSX-2, following treatment with a DNA methylation inhibitor," Prostate, vol. 67, no. 16, pp. 1781-1790, 2007.

[51] L. Zhao, D. C. Mou, J. R. Peng, L. Huang, Z. A. Wu, and X. S. Leng, "Diagnostic value of cancer-testis antigen mRNA in peripheral blood from hepatocellular carcinoma patients," World Journal of Gastroenterology, vol. 16, no. 32, pp. 40724078, 2010.

[52] O. Türeci, U. Sahin, I. Schobert et al., "The SSX-2 gene, which is involved in the $\mathrm{t}(\mathrm{X} ; 18)$ translocation of synovial sarcomas, codes for the human tumor antigen HOM-MEL-40," Cancer Research, vol. 56, no. 20, pp. 4766-4772, 1996.
[53] A. G. van Kessel, N. R. dos Santos, A. Simons et al., "Molecular cytogenetics of bone and soft tissue tumors," Cancer Genetics and Cytogenetics, vol. 95, no. 1, pp. 67-73, 1997.

[54] N. Naka, N. Araki, H. Nakanishi et al., "Expression of SSX genes in human osteosarcomas [2]," International Journal of Cancer, vol. 98, no. 4, pp. 640-642, 2002.

[55] M. Ayyoub, M. Brehm, G. Metthez et al., "SSX antigens as tumor vaccine targets in human sarcoma," Cancer Immunity, vol. 3, p. 13, 2003.

[56] N. H. Segal, N. E. Blachere, J. A. Guevara-Patiño et al., "Identification of cancer-testis genes expressed by melanoma and soft tissue sarcoma using bioinformatics.," Cancer Immunity, vol. 5, p. 2, 2005.

[57] N. Naka, S. Joyama, Y. Tsukamoto et al., "Quantification of SSX mRNA expression in human bone and soft tissue tumors using nucleic acid sequence-based amplification," Journal of Molecular Diagnostics, vol. 7, no. 2, pp. 187-197, 2005.

[58] C. H. Chen, G. J. Chen, H. S. Lee et al., "Expressions of cancer-testis antigens in human hepatocellular carcinomas," Cancer Letters, vol. 164, no. 2, pp. 189-195, 2001.

[59] F. L. Lim, M. Soulez, D. Koczan, H. J. Thiesen, and J. C. Knight, "A KRAB-related domain and a novel transcription repression domain in proteins encoded by SSX genes that are disrupted in human sarcomas," Oncogene, vol. 17, no. 15, pp. 2013-2018, 1998.

[60] E. Dimitriadis, D. Rontogianni, A. Kyriazoglou et al., "Novel SYT-SSX fusion transcript variants in synovial sarcoma," Cancer Genetics and Cytogenetics, vol. 195, no. 1, pp. 54-58, 2009.

[61] M. Soulez, A. J. Saurin, P. S. Freemont, and J. C. Knight, "SSX and the synovial-sarcoma-specific chimaeric protein SYTSSX co-localize with the human Polycomb group complex," Oncogene, vol. 18, no. 17, pp. 2739-2746, 1999.

[62] G. Cronwright, K. Le Blanc, C. Götherström, P. Darcy, M. Ehnman, and B. Brodin, "Cancer/testis antigen expression in human mesenchymal stem cells: down-regulation of SSX impairs cell migration and matrix metalloproteinase 2 expression," Cancer Research, vol. 65, no. 6, pp. 2207-2215, 2005.

[63] D. R. H. de Bruijn, N. R. dos Santos, E. Kater-Baats et al., "The cancer-related protein SSX2 interacts with the human homologue of a Ras-like GTPase interactor, RAB3IP, and a novel nuclear protein, SSX2IP," Genes Chromosomes and Cancer, vol. 34, no. 3, pp. 285-298, 2002.

[64] A. J. Crew, J. Clark, C. Fisher et al., "Fusion of SYT to two genes, SSX1 and SSX2, encoding proteins with homology to the Kruppel-associated box in human synovial sarcoma," EMBO Journal, vol. 14, no. 10, pp. 2333-2340, 1995.

[65] A. Kawai, J. Woodruff, J. H. Healey, M. F. Brennan, C. R. Antonescu, and M. Ladanyi, "SYT-SSX gene fusion as a determinant of morphology and prognosis in synovial sarcoma," New England Journal of Medicine, vol. 338, no. 3, pp. 153-160, 1998.

[66] L. Guillou, J. Benhattar, F. Bonichon et al., "Histologic grade, but not SYT-SSX fusion type, is an important prognostic factor in patients with synovial sarcoma: a multicenter, retrospective analysis," Journal of Clinical Oncology, vol. 22, no. 20, pp. 4040-4050, 2004.

[67] B. Skytting, G. Nilsson, B. Brodin et al., "A novel fusion gene, SYT-SSX4, in synovial sarcoma [3]," Journal of the National Cancer Institute, vol. 91, no. 11, pp. 974-975, 1999.

[68] B. Brodin, K. Haslam, K. Yang et al., "Cloning and characterization of spliced fusion transcript variants of synovial sarcoma: SYT/SSX4, SYT/SSX4v, and SYT/SSX2v. Possible 
regulatory role of the fusion gene product in wild type SYT expression," Gene, vol. 268, no. 1-2, pp. 173-182, 2001.

[69] B. Brodin, M. Törnkvist, K. Haslam, Y. Yunta. Xie, A. Bartolazzi, and O. Larsson, "Re: A novel fusion gene, SYT-SSX4, in synovial sarcoma," Journal of the National Cancer Institute, vol. 93, no. 17, pp. 1347-1349, 2001.

[70] M. F. C. Amary, T. C. Diss, and A. M. Flanagan, "Molecular characterization of a novel variant of a SYT-SSX1 fusion transcript in synovial sarcoma [6]," Histopathology, vol. 51, no. 4, pp. 559-561, 2007.

[71] G. Nilsson, B. Skytting, Y. Xie et al., "The SYT-SSX1 variant of synovial sarcoma is associated with a high rate of tumor cell proliferation and poor clinical outcome," Cancer Research, vol. 59, no. 13, pp. 3180-3184, 1999.

[72] C. R. Antonescu, A. Kawai, D. H. Leung et al., "Strong association of SYT-SSX fusion type and morphologic epithelial differentiation in synovial sarcoma," Diagnostic Molecular Pathology, vol. 9, no. 1, pp. 1-8, 2000.

[73] T. Saito, M. Nagai, and M. Ladanyi, "SYT-SSX1 and SYTSSX2 interfere with repression of E-cadherin by snail and slug: a potential mechanism for aberrant mesenchymal to epithelial transition in human synovial sarcoma," Cancer Research, vol. 66, no. 14, pp. 6919-6927, 2006.

[74] E. Batlle, E. Sancho, C. Franci et al., "The transcription factor Snail is a repressor of E-cadherin gene expression in epithelial tumour cells," Nature Cell Biology, vol. 2, no. 2, pp. 84-89, 2000.

[75] A. Cano, M. A. Pérez-Moreno, I. Rodrigo et al., "The transcription factor Snail controls epithelial-mesenchymal transitions by repressing E-cadherin expression," Nature Cell Biology, vol. 2, no. 2, pp. 76-83, 2000.

[76] M. Ishida, M. Miyamoto, S. Naitoh et al., "The SYT-SSX fusion protein down-regulates the cell proliferation regulator COM1 in $\mathrm{t}(\mathrm{x} ; 18)$ synovial sarcoma," Molecular and Cellular Biology, vol. 27, no. 4, pp. 1348-1355, 2007.

[77] H. Inagaki, T. Nagasaka, T. Otsuka, E. Sugiura, N. Nakashi$\mathrm{ma}$, and T. Eimoto, "Association of SYT-SSX fusion types with proliferative activity and prognosis in synovial sarcoma," Modern Pathology, vol. 13, no. 5, pp. 482-488, 2000.

[78] Y. Sun, B. Sun, J. Wang et al., "Prognostic implication of SYT-SSX fusion type and clinicopathological parameters for tumor-related death, recurrence, and metastasis in synovial sarcoma," Cancer Science, vol. 100, no. 6, pp. 1018-1025, 2009.

[79] X. Wei, Y. Sun, X. Zhao et al., "The influence of SYT-SSX fusion gene, E-cadherin and $\beta$-catenin on the metastasis of synovial sarcoma," Chinese Journal of Clinical Oncology, vol. 37, no. 4, pp. 205-208, 2010.

[80] M. Ladanyi, "Correlates of SYT-SSX fusion type in synovial sarcoma: getting more complex but also more interesting?" Journal of Clinical Oncology, vol. 23, no. 15, pp. 3638-3639, 2005.

[81] S. Takenaka, T. Ueda, N. Naka et al., "Prognostic implication of SYT-SSX fusion type in synovial sarcoma: a multi-institutional retrospective analysis in Japan," Oncology Reports, vol. 19, no. 2, pp. 467-476, 2008.

[82] Y. Xie, B. Skytting, G. Nilsson et al., "The SYT-SSX1 fusion type of synovial sarcoma is associated with increased expression of cyclin A and D1. A link between $\mathrm{t}(\mathrm{X} ; 18)(\mathrm{p} 11.2$; q11.2) and the cell cycle machinery," Oncogene, vol. 21, no. 37, pp. 5791-5796, 2002.

[83] C. Peng, W. Guo, Y. Yang, and H. Zhao, "Downregulation of ss18-ssx 1 expression by small interfering rna inhibits growth and induces apoptosis in human synovial sarcoma cell line
HS-SY-II in vitro," European Journal of Cancer Prevention, vol. 17, no. 5, pp. 392-398, 2008.

[84] Y. Xie, B. Skytting, G. Nilsson et al., "SYT-SSX is critical for cyclin D1 expression in synovial sarcoma cells: a gain of function of the $\mathrm{t}(\mathrm{X} ; 18)(\mathrm{p} 11.2 ; \mathrm{q} 11.2)$ translocation," Cancer Research, vol. 62, no. 13, pp. 3861-3867, 2002.

[85] M. Törnkvist, N. Natalishvili, Y. Xie et al., "Differential roles of SS18-SSX fusion gene and insulin-like growth factor-1 receptor in synovial sarcoma cell growth," Biochemical and Biophysical Research Communications, vol. 368, no. 3, pp. 793-800, 2008.

[86] D. Pretto, R. Barco, J. Rivera, N. Neel, M. D. Gustavson, and J. E. Eid, "The synovial sarcoma translocation protein SYTSSX2 recruits $\beta$-catenin to the nucleus and associates with it in an active complex," Oncogene, vol. 25, no. 26, pp. 36613669, 2006.

[87] A. Hecht and R. Kemler, "Curbing the nuclear activities of $\beta$-catenin: control over Wnt target gene expression," EMBO Reports, vol. 1, no. 1, pp. 24-28, 2000.

[88] A. E. Horvai, M. J. Kramer, and R. O’Donnell, “ $\beta$-catenin nuclear expression correlates with cyclin D1 expression in primary and metastatic synovial sarcoma: a tissue microarray study," Archives of Pathology and Laboratory Medicine, vol. 130, no. 6, pp. 792-798, 2006.

[89] F. Bozzi, A. Ferrari, T. Negri et al., "Molecular characterization of synovial sarcoma in children and adolescents: evidence of akt activation," Translational Oncology, vol. 1, no. 2, pp. 95-101, 2008.

[90] Y. Xie, M. Törnkvist, Y. Aalto et al., "Gene expression profile by blocking the SYT-SSX fusion gene in synovial sarcoma cells. Identification of XRCC4 as a putative SYT-SSX target gene," Oncogene, vol. 22, no. 48, pp. 7628-7631, 2003.

[91] P. D’Arcy, W. Maruwge, B. A. Ryan, and B. Brodin, "The oncoprotein SS18-SSX1 promotes p53 ubiquitination and degradation by enhancing HDM2 stability," Molecular Cancer Research, vol. 6, no. 1, pp. 127-138, 2008.

[92] P. D’Arcy, B. A. Ryan, and B. Brodin, "Reactivation of p53 function in synovial sarcoma cells by inhibition of p53HDM2 interaction," Cancer Letters, vol. 275, no. 2, pp. 285292, 2009.

[93] M. Tsuda, T. Watanabe, T. Seki et al., "Induction of p21WAF1/CIP1 by human synovial sarcoma-associated chimeric oncoprotein SYT-SSX1," Oncogene, vol. 24, no. 54, pp. 7984-7990, 2005.

[94] J. M. Lubieniecka, D. R. H. de Bruijn, L. Su et al., "Histone deacetylase inhibitors reverse SS18-SSX-mediated polycomb silencing of the tumor suppressor early growth response 1 in synovial sarcoma," Cancer Research, vol. 68, no. 11, pp. 43034310, 2008.

[95] D. R. H. de Bruijn, S. V. Allander, A. H. A. Van Dijk et al., "The synovial sarcoma-associated SS18-SSX2 fusion protein induces epigenetic gene (de)regulation," Cancer Research, vol. 66, no. 19, pp. 9474-9482, 2006.

[96] L. Su, H. Cheng, A. V. Sampaio, T. O. Nielsen, and T. M. Underhill, "EGR1 reactivation by histone deacetylase inhibitors promotes synovial sarcoma cell death through the PTEN tumor suppressor," Oncogene, vol. 29, no. 30, pp. 4352-4361, 2010.

[97] A. L. Sarver, H. Li, and S. Subramanian, "MicroRNA miR183 functions as an oncogene by targeting the transcription factor EGR1 and promoting tumor cell migration," Cancer Research, vol. 70, no. 23, pp. 9570-9580, 2010.

[98] L. Cironi, P. Provero, N. Riggi et al., "Epigenetic features of human mesenchymal stem cells determine their 
permissiveness for induction of relevant transcriptional changes by SYT-SSX1," PLoS ONE, vol. 4, no. 11, Article ID e7904, 2009.

[99] Y. Sun, D. Gao, Y. Liu, J. Huang, S. Lessnick, and S. Tanaka, "IGF2 is critical for tumorigenesis by synovial sarcoma oncoprotein SYT-SSX1," Oncogene, vol. 25, no. 7, pp. 1042- 1052, 2006.

[100] N. Friedrichs, J. Küchler, E. Endl et al., "Insulin-like growth factor-1 receptor acts as a growth regulator in synovial sarcoma," Journal of Pathology, vol. 216, no. 4, pp. 428-439, 2008.

[101] Y. Xie, B. Skytting, G. Nilsson, B. Brodin, and O. Larsson, "Expression of insulin-like growth factor-1 receptor in synovial sarcoma: association with an aggressive phenotype," Cancer Research, vol. 59, no. 15, pp. 3588-3591, 1999.

[102] R. Baserga, "The contradictions of the insulin-like growth factor 1 receptor," Oncogene, vol. 19, no. 49, pp. 5574-5581, 2000.

[103] S. V. Allander, P. B. Illei, Y. Chen et al., "Expression profiling of synovial sarcoma by cDNA microarrays: association of ERBB2, IGFBP2, and ELF3 with epithelial differentiation," American Journal of Pathology, vol. 161, no. 5, pp. 1587-1595, 2002.

[104] Y. F. Lee, M. John, S. Edwards et al., "Molecular classification of synovial sarcomas, leiomyosarcomas and malignant fibrous histiocytomas by gene expression profiling," British Journal of Cancer, vol. 88, no. 4, pp. 510-515, 2003.

[105] K. Baird, S. Davis, C. R. Antonescu et al., "Gene expression profiling of human sarcomas: insights into sarcoma biology," Cancer Research, vol. 65, no. 20, pp. 9226-9235, 2005.

[106] S. E. Steigen, D. F. Schaeffer, R. B. West, and T. O. Nielsen, "Expression of insulin-like growth factor 2 in mesenchymal neoplasms," Modern Pathology, vol. 22, no. 7, pp. 914-921, 2009.

[107] W. Cai, Y. Sun, W. Wang et al., "The effect of SYT-SSX and extracellular signal-regulated kinase (ERK) on cell proliferation in Synovial sarcoma," Pathology and Oncology Research, vol. 17, no. 2, pp. 357-367, 2011.

[108] S. Arisan, E. D. Buyuktuncer, N. Palavan-Unsal, T. Çaşkurlu, O. O. Çakir, and E. Ergenekon, "Increased expression of $\mathrm{EZH} 2$, a polycomb group protein, in bladder carcinoma," Urologia Internationalis, vol. 75, no. 3, pp. 252-257, 2005.

[109] O. P. Berezovska, A. B. Glinskii, Z. Yang, X. M. Li, R. M. Hoffman, and G. V. Glinsky, "Essential role for activation of the polycomb group $(\mathrm{PcG})$ protein chromatin silencing pathway in metastatic prostate cancer," Cell Cycle, vol. 5, no. 16, pp. 1886-1901, 2006.

[110] M. Mohty, A. S. M. Yong, R. M. Szydlo, J. F. Apperley, and J. V. Melo, "The polycomb group BMI1 gene is a molecular marker for predicting prognosis of chronic myeloid leukemia," Blood, vol. 110, no. 1, pp. 380-383, 2007.

[111] M. Sánchez-Beato, E. Sánchez, J. González-Carreró et al., "Variability in the expression of polycomb proteins in different normal and tumoral tissues. A pilot study using tissue microarrays," Modern Pathology, vol. 19, no. 5, pp. 684-694, 2006.

[112] W. J. Guo, M. S. Zeng, A. Yadav et al., "Mel-18 acts as a tumor suppressor by repressing Bmi-1 expression and down-regulating Akt activity in breast cancer cells," Cancer Re-search, vol. 67, no. 11, pp. 5083-5089, 2007.

[113] N. R. dos Santos, D. R. H. de Bruijn, E. Kater-Baats, A. P. Otte, and A. G. Van Kessel, "Delineation of the protein domains responsible for SYT, SSX, and SYT-SSX nuclear localization," Experimental Cell Research, vol. 256, no. 1, pp. 192-202, 2000.
[114] R. Barco, C. B. Garcia, and J. E. Eid, "The synovial sarcomaassociated SYT-SSX2 oncogene antagonizes the polycomb complex protein Bmil," PLoS ONE, vol. 4, no. 4, Article ID e5060, 2009.

[115] T. Ito, M. Ouchida, Y. Morimoto et al., "Significant growth suppression of synovial sarcomas by the histone deacetylase inhibitor FK228 in vitro and in vivo," Cancer Letters, vol. 224, no. 2, pp. 311-319, 2005.

[116] M. Nagai, S. Tanaka, M. Tsuda et al., "Analysis of transforming activity of human synovial sarcoma-associated chimeric protein SYT-SSX1 bound to chromatin remodeling factor hBRM/hSNF2 $\alpha$," Proceedings of the National Academy of Sciences of the United States of America, vol. 98, no. 7, pp. 38433848, 2001.

[117] R. Barco, L. B. Hunt, A. L. Frump et al., "The synovial sarcoma SYT-SSX2 oncogene remodels the cytoskeleton through activation of the ephrin pathway," Molecular Biology of the Cell, vol. 18, no. 10, pp. 4003-4012, 2007.

[118] Y. Dobashi, S. Suzuki, E. Sato, Y. Hamada, T. Yanagawa, and A. Ooi, "EGFR-dependent and independent activation of Akt/mTOR cascade in bone and soft tissue tumors," Modern Pathology, vol. 22, no. 10, pp. 1328-1340, 2009.

[119] N. Friedrichs, M. Trautmann, E. Endl et al., "Phosphatidylinositol-3'-kinase/AKT signaling is essential in synovial sarcoma," International Journal of Cancer, vol. 129, no. 7, pp. 1564-1575, 2011.

[120] C. Palman, D. F. Bowen-Pope, and J. J. Brooks, "Plateletderived growth factor receptor ( $\beta$-subunit) immunoreactivity in soft tissue tumors," Laboratory Investigation, vol. 66, no. 1, pp. 108-115, 1992.

[121] M. C. Heinrich, D. J. Griffith, B. J. Druker, C. L. Wait, K. A. Ott, and A. J. Zigler, "Inhibition of c-kit receptor tyrosine kinase activity by STI 571 a selective tyrosine kinase inhibitor," Blood, vol. 96, no. 3, pp. 925-932, 2000.

[122] V. Barbashina, J. Benevenia, H. Aviv et al., "Oncoproteins and proliferation markers in synovial sarcomas: a clinicopathologic study of 19 cases," Journal of Cancer Research and Clinical Oncology, vol. 128, no. 11, pp. 610-616, 2002.

[123] G. D. Demetri, M. Von Mehren, C. D. Blanke et al., "Efficacy and safety of imatinib mesylate in advanced gastrointestinal stromal tumors," New England Journal of Medicine, vol. 347, no. 7, pp. 472-480, 2002.

[124] E. Tamborini, L. Bonadiman, A. Greco et al., "Expression of Ligand-Activated KIT and Platelet-Derived Growth Factor Receptor $\beta$ Tyrosine Kinase Receptors in Synovial Sarcoma," Clinical Cancer Research, vol. 10, no. 3, pp. 938-943, 2004.

[125] J. Verweij, P. G. Casali, J. Zalcberg et al., "Progression-free survival in gastrointestinal stromal tumours with high-dose imatinib: randomised trial," The Lancet, vol. 364, no. 9440, pp. 1127-1134, 2004.

[126] D. G. Thomas, T. J. Giordano, D. Sanders et al., "Expression of receptor tyrosine kinases epidermal growth factor receptor and HER-2/ neu in synovial sarcoma," Cancer, vol. 103, no. 4, pp. 830-838, 2005.

[127] J. A. López-Guerrero, S. Navarro, R. Noguera et al., "Mutational analysis of the c-KIT and PDGFR $\alpha$ in a series of molecularly well-characterized synovial sarcomas," Diagnostic Molecular Pathology, vol. 14, no. 3, pp. 134-139, 2005.

[128] L. Krsková, M. Kalinová, H. Břízová, M. Mrhalová, D. Sumerauer, and R. Kodet, "Molecular and immunohistochemical analyses of BCL2, KI-67, and cyclin D1 expression in synovial sarcoma," Cancer Genetics and Cytogenetics, vol. 193, no. 1, pp. 1-8, 2009. 
[129] B. Rikhof, S. de Jong, A. J. H. Suurmeijer, C. Meijer, and W. T. A. Van Der Graaf, "The insulin-like growth factor system and sarcomas," Journal of Pathology, vol. 217, no. 4, pp. 469-482, 2009.

[130] H. V. Erkizan, Y. Kong, M. Merchant et al., "A small molecule blocking oncogenic protein EWS-FLI1 interaction with RNA helicase A inhibits growth of Ewing's sarcoma," Nature Medicine, vol. 15, no. 7, pp. 750-756, 2009.

[131] F. M. Raaphorst, "Deregulated expression of polycombgroup oncogenes in human malignant lymphomas and epithelial tumors," Human Molecular Genetics, vol. 14, no. 1, pp. R93-R100, 2005.

[132] Y. Takihara, "Role of Polycomb-group genes in sustaining activities of normal and malignant stem cells," International Journal of Hematology, vol. 87, no. 1, pp. 25-34, 2008.

[133] M. Dimri, P. V. Bommi, A. A. Sahasrabuddhe, J. D. Khandekar, and G. P. Dimri, "Dietary omega-3 polyunsaturated fatty acids suppress expression of EZH2 in breast cancer cells," Carcinogenesis, vol. 31, no. 3, pp. 489-495, 2010.

[134] C. D. Kemp, M. Rao, S. Xi et al., "Polycomb repressor complex-2 is a novel target for mesothelioma therapy," Clinical Cancer Research, vol. 18, no. 1, pp. 77-90, 2012.

[135] I. Ray-Coquard, A. Le Cesne, J. S. Whelan et al., "A phase II study of gefitinib for patients with advanced HER-1 expressing synovial sarcoma refractory to doxorubicin-containing regimens," Oncologist, vol. 13, no. 4, pp. 467-473, 2008.

[136] R. Chugh, J. K. Wathen, R. G. Maki et al., "Phase II multicenter trial of imatinib in 10 histologic subtypes of sarcoma using a bayesian hierarchical statistical model," Journal of Clinical Oncology, vol. 27, no. 19, pp. 3148-3153, 2009.

[137] S. R. Grossman, M. Perez, A. L. Kung et al., "p300/MDM2 complexes participate in MDM2-mediated p53 degradation," Molecular Cell, vol. 2, no. 4, pp. 405-415, 1998.

[138] E. S. Silverman, J. Du, A. J. Williams, R. Wadgaonkar, J. M. Drazen, and T. Collins, "cAMP-response-element-bindingprotein-binding protein (CBP) and p300 are transcriptional co-activators of early growth response factor-1 (Egr-1)," Biochemical Journal, vol. 336, no. 1, pp. 183-189, 1998.

[139] A. Hoffmeister, A. Ropolo, S. Vasseur et al., "The HMG-I/Yrelated protein $\mathrm{p} 8$ binds to $\mathrm{p} 300$ and Pax 2 trans-activation domain-interacting protein to regulate the trans-activation activity of the Pax $2 \mathrm{~A}$ and Pax $2 \mathrm{~B}$ transcription factors on the glucagon gene promoter," Journal of Biological Chemistry, vol. 277, no. 25, pp. 22314-22319, 2002.

[140] C. Ratineau, M. W. Petry, H. Mutoh, and A. B. Leiter, "Cyclin D1 represses the basic helix-loop-helix transcription factor, BETA2/NeuroD," Journal of Biological Chemistry, vol. 277, no. 11, pp. 8847-8853, 2002.

[141] J. Yu, I. de Belle, H. Liang, and E. D. Adamson, "Coactivating factors p300 and CBP are transcriptionally crossregulated by Egr1 in prostate cells, leading to divergent responses," Molecular Cell, vol. 15, no. 1, pp. 83-94, 2004.

[142] N. Minsky and M. Oren, "The RING domain of Mdm2 mediates histone ubiquitylation and transcriptional repression," Molecular Cell, vol. 16, no. 4, pp. 631-639, 2004.

[143] H. W. Lo, S. C. Hsu, M. Ali-Seyed et al., "Nuclear interaction of EGFR and STAT3 in the activation of the iNOS/NO pathway," Cancer Cell, vol. 7, no. 6, pp. 575-589, 2005.

[144] M. Hall, S. Bates, and G. Peters, "Evidence for different modes of action of cyclin-dependent kinase inhibitors: p15 and p16 bind to kinases, p21 and p27 bind to cyclins," Oncogene, vol. 11, no. 8, pp. 1581-1588, 1995.

[145] B. E. Sawaya, K. Khalilit, W. E. Mercer, L. Denisova, and S. Amini, "Cooperative actions of HIV-1 Vpr and p53 modulate viral gene transcription," Journal of Biological Chemistry, vol. 273, no. 32, pp. 20052-20057, 1998.

[146] C. Ohlsson, N. Kley, H. Werner, and D. Leroith, "p53 regulates insulin-like growth factor-I (IGF-I) receptor expression and IGF-I-induced tyrosine phosphorylation in an osteosarcoma cell line: interaction between $\mathrm{p} 53$ and Sp1," Endocrinology, vol. 139, no. 3, pp. 1101-1107, 1998.

[147] X. Zhang and Y. Liu, "Suppression of HGF receptor gene expression by oxidative stress is mediated through the interplay between Sp1 and Egr-1," American Journal of PhysiologyRenal Physiology, vol. 284, no. 6, pp. F1216-F1225, 2003.

[148] G. L. Bond, W. Hu, E. E. Bond et al., "A single nucleotide polymorphism in the MDM2 promoter attenuates the p53 tumor suppressor pathway and accelerates tumor formation in humans," Cell, vol. 119, no. 5, pp. 591-602, 2004.

[149] S. S. Clair, L. Giono, S. Varmeh-Ziaie et al., "DNA damageinduced downregulation of $\mathrm{Cdc} 25 \mathrm{C}$ is mediated by $\mathrm{p} 53$ via two independent mechanisms: one involves direct binding to the cdc25C promoter," Molecular Cell, vol. 16, no. 5, pp. 725736, 2004.

[150] S. Sengupta, A. Shimamoto, M. Koshiji et al., "Tumor suppressor p53 represses transcription of RECQ4 helicase," Oncogene, vol. 24, no. 10, pp. 1738-1748, 2005.

[151] T. Ravasi, H. Suzuki, C. V. Cannistraci et al., "An atlas of combinatorial transcriptional regulation in mouse and man," Cell, vol. 140, no. 5, pp. 744-752, 2010.

[152] D. R. H. de Bruijn, A. H. A. van Dijk, M. P. Willemse, and A. G. van Kessel, "The C terminus of the synovial sarcomaassociated SSX proteins interacts with the LIM homeobox protein LHX4," Oncogene, vol. 27, no. 5, pp. 653-662, 2008.

[153] J. F. Rual, K. Venkatesan, T. Hao et al., "Towards a proteomescale map of the human protein-protein interaction network," Nature, vol. 437, no. 7062, pp. 1173-1178, 2005. 


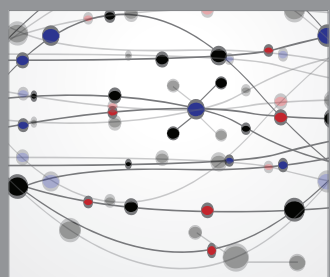

The Scientific World Journal
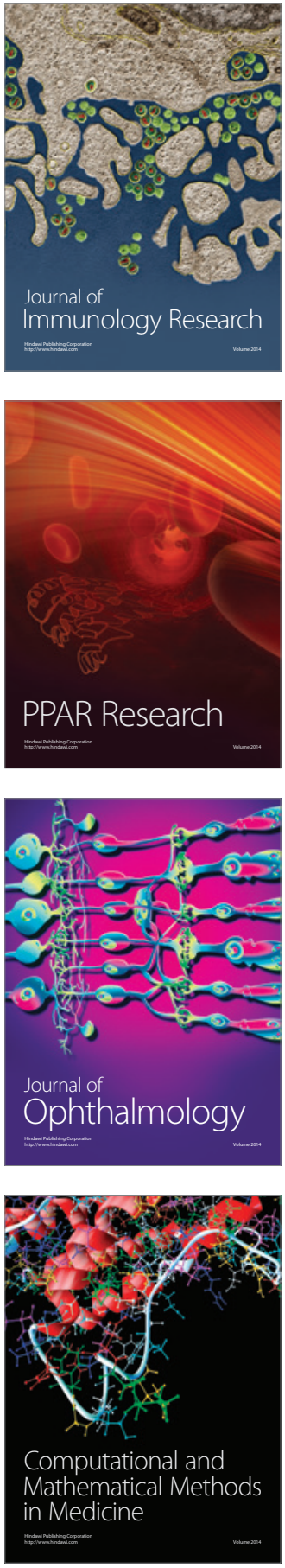

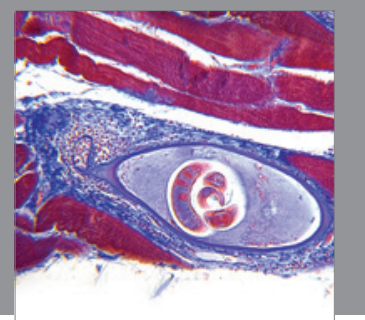

Gastroenterology

Research and Practice
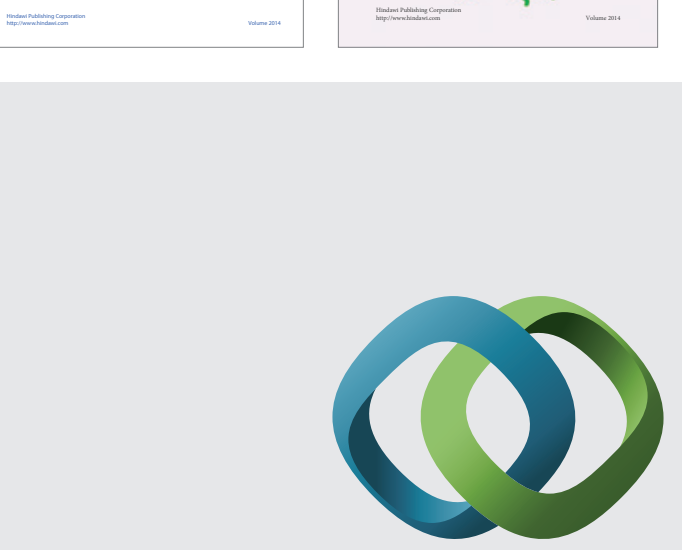

\section{Hindawi}

Submit your manuscripts at

http://www.hindawi.com
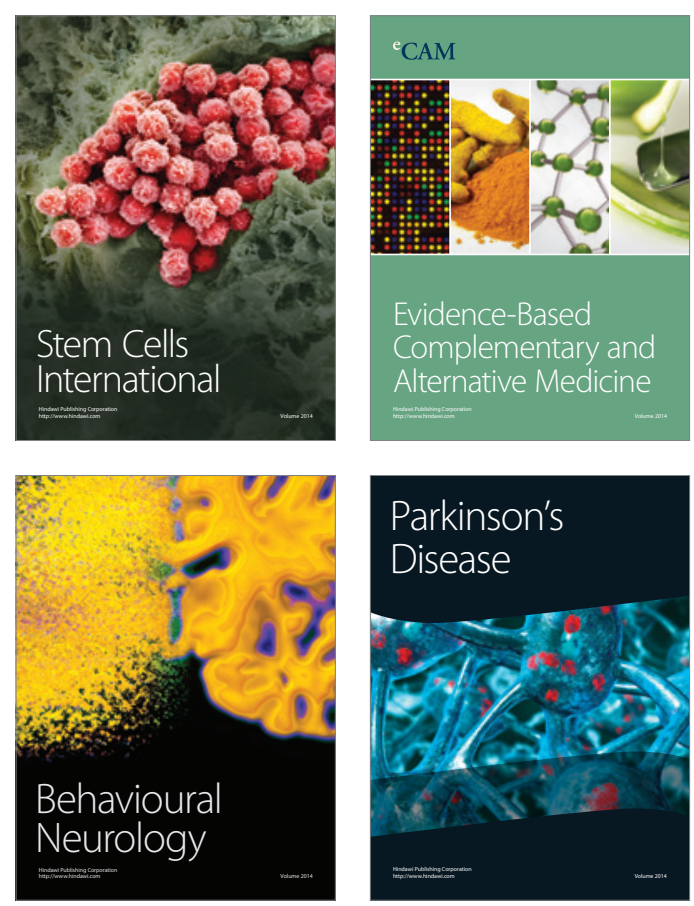

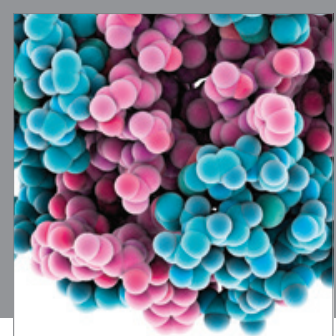

Journal of
Diabetes Research

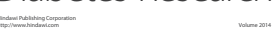

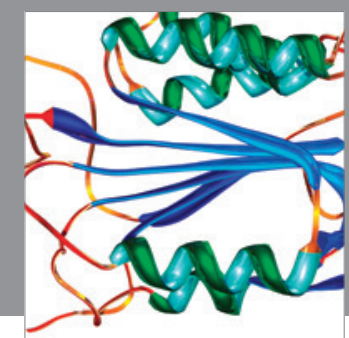

Disease Markers
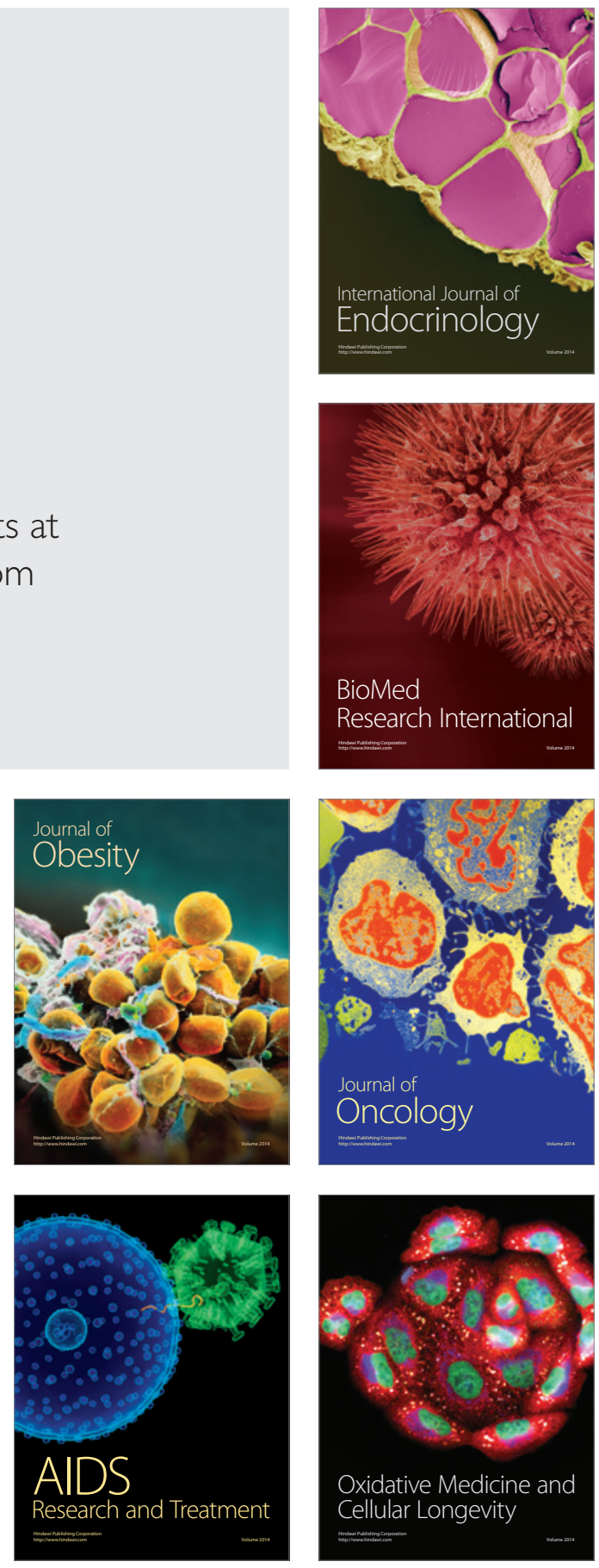